\section{Poética das diferenças em contextos urbanos}

Isadora Lins França. Consumindo lugares, consumindo nos lugares: homossexualidade, consumo e subjetividades na cidade de Sáo Paulo. Rio de Janeiro, Eduerj, 2012. 274 páginas.

\section{Roberto Marques}

Em seu livro Consumindo lugares, consumindo nos lugares: homossexualidade, consumo e subjetividades na cidade de São Paulo, Isadora Lins França parte de dados etnográficos colhidos em lugares de lazer noturno na cidade de São Paulo a fim de entender "processos de diferenciação e subjetivação relacionados ao consumo e à homossexualidade em sua dimensão plural" (p. 17). Para isso, realiza um trabalho de pesquisa rigoroso e sensível em três lugares distintos: a boate The Week; os encontros voltados para o público conhecido como "ursos" ao redor do espaço conhecido como Ursound; e um samba GLS (Gay, Lésbicas e Simpatizantes) chamado Boteco do Caê e seus espaços contíguos, na região do Largo do Arouche.

Ao apostar na diversificação de opçóes para o público LGBT (Lésbicas, Gays, Bissexuais, Travestis e Transgêneros) como realidade deflagradora de sua pesquisa, Isadora França reconhece a importância da segmentação do mercado voltado a esse público nas duas últimas décadas. Os efeitos de superfície da "São Paulo de hoje"1 são percebidos na consolidação e dinâmica de sistemas de nomeação particulares, nas formas de cada um dos frequentadores desses diferentes lugares construir narrativas sobre si mesmos, consolidando estéticas e estilos condizentes.

Essas formas de subjetivação legitimam trânsitos entre pares, inspiram jeitos de corpo, induzem posicionamentos físicos e hierárquicos nesses locais de lazer onde se está por vontade própria, por afinidade ou pela pretensa possibilidade de "ser quem realmente se é". Nesse sentido, o trabalho aproxima de forma inovadora as temáticas do lazer, consumo e processos de identificação e subjetivação, articulando-os de forma dinâmica, multifacetada e complexa.

É justo dizer que a autora encontra inspiração em uma série de trabalhos etnográficos ocorridos em grandes centros urbanos do país, notadamente Rio de Janeiro e São Paulo, enfocando a consolidação e os complexos jogos de identificação nas práticas homossexuais. Ao mesmo tempo em que conversa com essa produção, França contribui de forma inovadora com os estudos de gênero e sexualidade ao devotar esforços em uma escrita que coteje os efeitos da diversificação e diferenciação de mercado, afastando a possibilidade de pensar seus interlocutores como membros de uma comunidade ordenada univocamente pelo desejo, como um suposto mundo à parte ou por oposição à ideia de heterossexualidade.

No panorama recente descrito por França, o objeto de desejo na Ursound é estigmatizado na boate The Week; os objetos que possibilitam trânsitos e atração no Boteco do Caê embaralham e subvertem os marcadores convencionais de masculinidade, potencial de consumo, raça e aparência física tomados como ideais naquela boate. As formas de construção da masculinidade se opóem entre "ursos" e frequentadores das raves.

Enfeixando em uma mesma pesquisa essa diversidade de experiências, França propóe, a partir de sua etnografia, um espelhamento entre lugares do mercado LGBT, ressaltando as responsabilidades que tal pulverização impóe aos frequentadores de cada um desses ambientes ao exigir deles escolhas, fidelidades, cuidados, incorporaçóes que os tornem objetos de desejos.

Isadora França nos convida a pensar, portanto, não em uma linguagem ou identidade gay como campos pacíficos da articulação entre pessoas à margem da heteronormatividade, mas como sistemas de nomeação e práticas que articulam corpos e pertenças em meio à diversidade de marcadores disponíveis em cada um desses ambientes.

Nessa poética da(s) diferença(s), como articular a si mesmo para potencializar atributos e afinidades nesses locais onde supostamente se pode(ria) ser o que realmente se é? Como essas articulaçóes implicam em identificações, deslocamentos e diferenciação com patentes implicações no consumo e na política? Em uma palavra, França nos fala das agências desses/dos lugares sobre nós, objetos consumidos: "Longe de serem apenas cenários neutros, os lugares atuam na constituição de subjetividades ao mesmo tempo que são constituídos por seus frequentadores" (p. 19), ensina-nos. 
No capítulo inicial de seu livro, a autora apresenta um "mapa da pesquisa", em que pontua influências teóricas e autores citados, assim como a ligação criativa e particular que estabelece com eles.

Aqui, marcadores de gênero e sexualidade são remetidos à própria noção de diferença, alçando-nos à ideia forte da reflexão antropológica. Por outro lado, os avanços nesse campo, notadamente para a antropologia urbana, são conduzidos a partir de um diálogo interdisciplinar com a geografia feminista. Pela análise concreta do espaço, pretende-se demonstrar como o mesmo lugar pode ganhar significados e escalas diferenciadas a partir da precipitaçáo de marcadores como gênero, cor/ raça, idade, sexualidade e classe (p. 27, passim). A partir dessa ideia, a autora entrevê uma ligação entre a análise do espaço e as teorias de Alfred Gell e Daniel Miller, para quem o consumo de bens é tomado como atributo "de alguma personalidade individual, insígnias de identidade [...] e compromissos interpessoais específicos" (Gell apud França, p. 28) ou como forma expressiva da projeção (de si) sobre um mundo externo e a posterior introjeção dessas projeçóes, materializadas a partir de objetos.

Recorre-se, portanto, ao alinhamento da reflexão sobre gênero e sexualidade, à análise concreta de significação do espaço e à aproximação com a antropologia do consumo para a construçáo das questōes deflagradoras da pesquisa. A partir de entâo, ambientes de lazer - possivelmente mais que as ideias usuais de casa, comunidade, bairro, localidade - tornam-se locus privilegiado da reflexão sobre formas de subjetivação nas últimas décadas.

Ao tentar apreender esse jogo de projeçóes, introjeçóes e insígnias a partir dos usos criativos empreendidos pelos sujeitos para falar de si, de seus ideais e desejos, França demonstra como, a partir de contextos específicos materializados em produção de estilos, constituem-se subjetividades e diferenciaçóes sociais, produz-se a um só tempo subjetividades e lugares. É essa dinâmica que podemos acompanhar nos capítulos etnográfico, pontuados a seguir.

Entre os lugares etnografados, provavelmente a boate The Week seja o ambiente em que a importância do cálculo racional para a produçáo de estilo possa ser percebido de forma mais evidente. É ali que a autora inicia sua escrita, em um ambiente de forte fluxo de informaçôes nacionais e internacionais sobre a noite gay, em que as ideias de diversão, investimento financeiro e profissionalismo inspiram atitudes, consumo e escolhas de forma que a constante demarcaçáo de (diferenciaçáo de) prestígio seja evidenciada.

Em uma formulação sintética dessa relação, a autora nos adverte que, ainda que consideremos que esse desejo de distinção não abarque todos os frequentadores da The Week, é evidente que ele "marca o lugar e seus sistemas de produçáo de diferenças [...] orientando também a dinâmica de produção dos desejos" (p. 93, passim). Dessa forma, o corpo bombado, o uso de marcas e substâncias recreativas específicas, a referência constante a viagens e festas consolidam um texto ideal para a produção da diferenciação e hierarquia.

Tais insígnias não funcionam simplesmente como formas de identidades prêt-à-porter, como se poderia pensar a partir de um mau uso da relação entre antropologia e consumo. Elas agenciam e ressaltam fronteiras de classe social, cor/raça, origem social. Elas possibilitam a confluência de uma estética afeita à classe média urbana, borrando fronteiras entre esse lugar do universo LGBT e trânsitos profissionais, familiares e outros, mais convencionais.

Ao tempo, amalgamadas aos marcadores citados acima, os objetos que compóem o texto ideal para transitar no "universo perfeito" ${ }^{2} \mathrm{da}$ boate produzem estranhamento quando apropriados por outros corpos. A produçáo dessa sensibilidade regula, portanto, o uso de determinados objetos pelos "morenos", pelos "caras do interior", como apontam interlocutores da pesquisa na boate.

Dessa forma produz-se, por oposição, as identificações da "bicha" e do "cafuçu", como formas de subjetivação periféricas, com trânsito restrito, náo afeito aos ideais de consumo, jeitos de corpo, agência, origem, uso de grifes e demais marcas de diferenciação.

Se a face apolínea dos frequentadores das camadas médias urbanas agrupadas na The Week tornou-se uma imagem frequente no mercado LGBT, talvez seja possível afirmar que é em diálogo com ela que homens grandes, peludos e corpulentos tentam construir outra forma de visibilizaçáo para seu erotismo e afetividade. A partir dos dados colhidos nas festas dos "ursos", percebe-se a resistência às re- 
laçóes inspiradas unicamente pelo desejo sexual e fugacidade; o apego a um corpo mais natural e a um visual despojado, conjugando valores bastante distintos dos marcadores que caracterizam e consolidam o desejo na The Week.

Em contraste com o "universo perfeito" de sensaçôes e estéticas calculadas minuciosamente na boate, revela-se na Ursound um investimento distinto na busca de um ideal de masculinidade para homens que se relacionam com homens. Essa busca precipita categorias múltiplas e associaçóes variadas entre estéticas e posiçóes no ambiente.

Em oposição a um texto e estética minuciosamente calculados e padróes de pertença bastante rígidos, a busca de um corpo e visual mais despojados permite aos "ursos" mobilizar um leque mais amplo de frequentadores nas festas, a partir de categorias pouco distintivas como "chasers" (aquele que admira e deseja ursos) ou "paizão" (homem gay mais maduro). Revela a autora (p. 160):

Essa fluidez e a erotização de homens que são convencionalmente tidos como pouco atraentes geram um paradoxo curioso: para alguns, a festa é tida como fetichista, no sentido de que iriam a ela os que se interessam apenas por pessoas de determinado tipo físico [...]; para outros a festa peca na falta de identificação com os ursos justamente por abarcar um público variado que se sente rejeitado em outros lugares do mercado segmentado de lazer noturno voltado para homens que se relacionam afetivo-sexualmente com outros homens.

Aprofundando o cotejamento entre os dois grupos etnografados até agora, a autora pontua os distintos investimentos realizados em torno da ideia de masculinidade. Percebe-se que os marcadores em que repousam momentaneamente as imagens acentuadas do masculino são elas mesmas contextuais e mobilizadas criativamente por agentes em interação.

De forma análoga à reflexáo empreendida a partir da The Week, poderíamos dizer que, embora as convenções de imagens do masculino não englobem a todos na Ursound, elas se impóem a partir de marcadores pelos quais os "ursos" se co- municam, deflagram temas e posicionamentos nas interaçôes entre agentes, dando oportunidade para que potências sejam reforçadas ou apagadas a partir de interações contínuas nas festas.

Tal observação ressalta uma forma específica de segmentaçáo do mercado na "São Paulo de hoje" e como esse mercado entre homens que se relacionam afetiva e sexualmente com outros homens se beneficia da recepção particular de uma imagética de consumo de padrōes internacionais, ou com número ampliado de possibilidades de testar situaçóes e contextos. Como afirma um informante citado no livro: "Antes eu achava que eu era um ET que gostava de mais velhos. Agora, vejo que tem um monte de 'ET'” (p. 156).

É interessante o contraste estabelecido entre esses diferentes lugares marcados por trânsitos e consumo das camadas médias e um "samba GLS" no Largo do Arouche.

O Boteco do Caê se situa em um cenário de afluxo constante de pessoas no centro da cidade, próximo a bares, cinemas e metrôs, em uma sobreposição de usos que denotam as ideias de variedade e consumo em tons bastante distintos dos analisados anteriormente. Ali, moradores do centro e trabalhadores das periferias de São Paulo, de diferentes cores e preferências sexuais, dançam variados ritmos com apelo popular. $\mathrm{O}$ uso cotidiano desses espaços por uma população bastante diversificada, a dinâmica de interaçấo dessas pessoas em meio a essa diversidade e os novos fluxos ali presentes nos momentos de lazer estabelecem um cenário particularmente interessante.

No Boteco do Caê, estilo e uso de objetos e a habilidade no dançar diferenciam posiçóes, definem "os de fora" e "os de dentro", ordenando olhares, conduzindo investimentos em jeitos e potências do corpo. É nesse ambiente que, pela primeira vez no livro, a ideia de "bicha" e ainda "bicha preta" aparece como potência do corpo, como habilidade na dança, habilidade possuída por alguns e almejada pelos demais (p. 204, passim). Tal confluência entre estética, música e negritude, faz-nos perceber França, possui decorrências políticas visíveis, assim como efeitos nos ordenamentos do desejo, posiçóes sociais, na produçấo de subjetivaçóes, parcerias e narrativas. É também nesse ambiente que a oposi- 
ção masculino/feminino e bicha/mano parecem ter implicaçóes diretas sobre os desempenhos de diferentes convençóes entre masculino e feminino em corpos de homens. França levanta dados bastante singulares da filiação entre registros de masculinidade/feminilidade em periferias urbanas, revisitando as proposiçóes fundadoras do campo no Brasil realizadas por Fry (1982).

Longe de uma suposta sobreposição unívoca entre os pares masculino-atividade (Fry, 1982) e feminino-passividade, descreve deslocamentos espaciais, conformaçóes de convençóes de gênero e sexualidade, processos de identificação e educação sentimental bastante complexos e singulares. Mostra também como objetos são utilizados para induzir dimensóes subjetivas, seja por justaposição entre objetos, por deslocamentos, seja a partir de seus usos criativos.

A descrição ganha contornos ainda mais fortes em diálogo com os dados explorados na boate The Week e nas festas da Ursound.

Em meio a lugares tão distintos, aproximados pela escrita, há uma busca constante de pensar a partir do estabelecimento do desejo e da(s) diferença(s), de como a conformação de si e do outro a partir desses jogos estabelece potências políticas de identificação, seja pela raça, pela possibilidade de trânsito e deslocamento, pelo consumo, entre outros. Mostra-se também de forma contundente como tais jogos se materializam em termos, corpos, estilos e objetos do desejo, sejam eles humanos ou não humanos.

Dessa forma, embalados pela escrita, vamos percebendo ao longo dos deslocamentos provocados pela autora como objetos e lugares fornecem experiências e experimentaçóes, como despertam narrativas inspiradoras sobre formas de subjetivação na relação com os espaços. Em patente consonância com a antropologia contemporânea, Consumindo lugares, consumindo nos lugares revela novos alcances para temas bastante caros à antropologia clássica. Revela ainda, de forma inelutável para nós, cientistas sociais, aquilo que os interlocutores de Isadora França em campo parecem saber de cor: como objetos e lugares são a própria carne no engenho e dinâmica de "ser quem realmente se é".

\section{Notas}

1 Expressão utilizada por Júlio Simões no prefácio do livro.

2 Slogan utilizado pela The Week em material de divulgação (França, p. 75).

\section{BIBLIOGRAFIA}

FRY, Peter, Para inglês ver. Rio de Janeiro, Zahar, 1982.

ROBERTO MARQUES é professor do Departamento de Ciências Sociais da Universidade Regional do Cariri, pós-doutorando pelo Programa de Pós-Graduação em Sociologia e Antropologia da Universidade Federal do Rio de Janeiro e bolsista do CNPq. E-mail: r-marques01@uol.com.br.

DOI: http//dx.doi.org/10.17666/3087180-183/2015 


\section{revista}

\section{sociologia \&antropologia}

VOLUME O4 NÚMERO O2 JULHO-DEZEMBRO DE 2014 SEMESTRAL

ISSN 2236-7527

ISSN 2238-3875 (ONLINE)
Sociologia \& Antropologia Revista do PPGSA

Programa de Pós-Graduação em Sociologia e Antropologia/UFRJ

Lgo. do São Francisco de Paula, I, sala 420 2005I-070 Rio de Janeiro RJ

$\mathrm{t} / \mathrm{fax}+55$ (2I) 2224-8965 ramal 2 I 5

revistappgsa@gmail.com

www.revistappgsa.ifcs.ufrj.br

\author{
A ANTROPOLOGIA COMO PARTICIPANTE DE UMA \\ GRANDE CONVERSA PARA MOLDAR O MUNDO. \\ ENTREVISTA COM TIM INGOLD \\ Clara Mafra (in memoriam), Octavio Bonet, \\ Otávio Velho e Rosane Prado
}

ITINERAÇÕES E MALHAS PARA PENSAR OS ITINERÁRIOS DE CUIDADO. A PROPÓSITO DE TIM INGOLD

Octavio Bonet

ETNOLOGIA E FENOMENOLOGIA. UM COMENTÁRIO DAS OBRAS DE MARCELO BÓRMIDA, TIM INGOLD E EDUARDO VIVEIROS DE CASTRO

Rolando Silla

PRÁTICAS DA ARTE CONTEMPORÂNEA: UMA ABORDAGEM PRAGMÁTICA A UM NOVO PARADIGMA ARTÍSTICO

Nathalie Heinich

LENDO E AGENCIANDO IMAGENS: O REI, A NATUREZA E SEUS BELOS NATURAIS

Lilia Moritz Schwarcz

DESIGUALDADES NAS TRANSIÇÕES PARA A VIDA ADULTA NO BRASIL (1996 E 2008)

Carlos Antonio Costa Ribeiro

GRACILIANO RAMOS E SUAS MEMÓRIAS DO CÁRCERE: CICATRIZES

Marcelo Ridenti

CASAMENTOS INVERTIDOS: ACUSAÇÕES E PRECONCEITOS EM ARRANJOS CONJUGAIS DESVIANTES

Mirian Goldenberg

ROCK AND ROLL, JOHN LENNON E A ESFERA PÚBLICA

Luis Carlos Fridman

REPERTÓRIOS MORAIS E ESTRATÉGIAS INDIVIDUAIS DE BENEFICIÁRIOS E CADASTRADORES DO BOLSA FAMÍLIA Mani Tebet Marins

JONATHAS ABBOTT: INDIVIDUALIDADE E COLECIONISMO NA BAHIA NO SÉCULO XIX

Cláudia de Oliveira

RESENHA

"A DOMINAÇÃO" DE MAX WEBER PELOS SEUS MANUSCRITOS INACABADOS (1911 - 1913)

La domination. (2013). Max Weber. (trad. Isabelle Kalinowski). Paris: La Découverte, 432 p.

Mariana Barreto 